Supporting information

\title{
Bioluminescence-Triggered Photoswitchable Bacterial Adhesions enable Higher Sensitivity and Dual-readout Bacterial Biosensors for Mercury
}

Fei Chen,,${ }^{1+}$ Rachel L. Warnock,,${ }^{2,}$ Jan Roelof Van der Meer, ${ }^{3}$ Seraphine V. Wegner ${ }^{1, *}$

${ }^{1}$ Institute of Physiological Chemistry and Pathobiochemistry, University of Münster, 48149 Münster, Germany

${ }^{2}$ Max Planck Institute for Polymer Research, Ackermannweg 10, 55128 Mainz, Germany

${ }^{3}$ Department of Fundamental Microbiology, University of Lausanne, 1015, Lausanne, Switzerland. 


\section{Table of Contents}

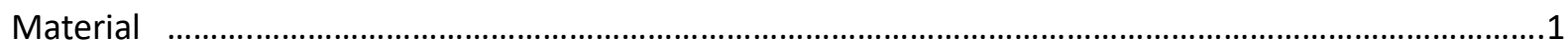

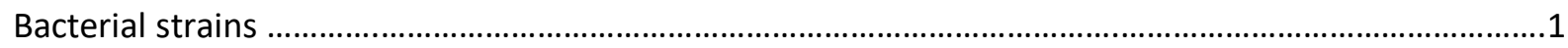

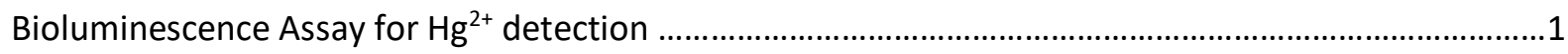

Kinetics change of bacterial bioluminescence .........................................................................................

Photoactivation of nMagHigh protein with bioluminescent bacteria .....................................................

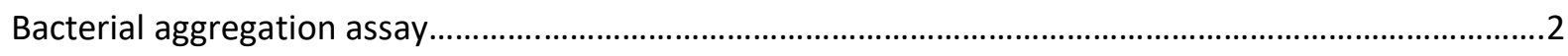

Mercury detection in an environmental sample doped with mercury ……..............................................

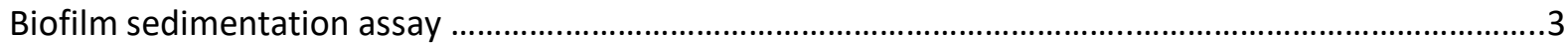

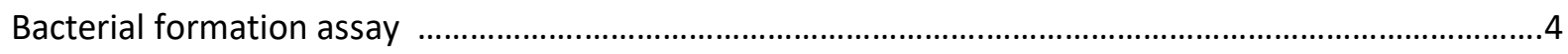

Figure S1

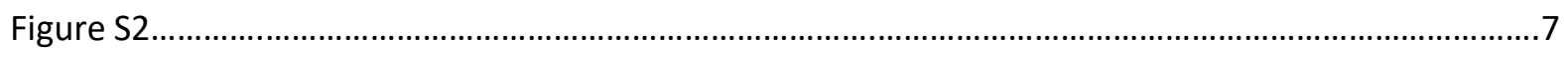

Figure S3

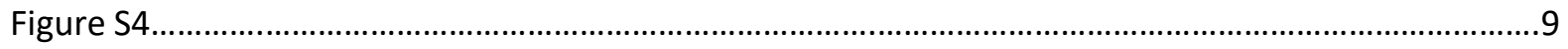

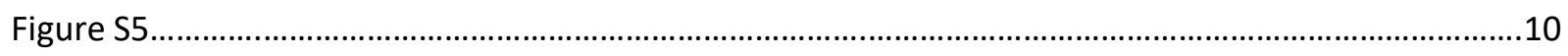

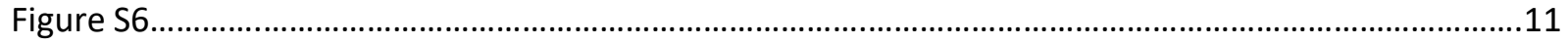




\section{Material.}

The plasmid pB33eCPX, which contains the gene for the enhanced circularly permutated outer membrane

protein OmpX (eCPX), was a gift from Prof. Patrick Daugherty (Addgene plasmid \# 23336). ${ }^{1}$ The photoswitchable proteins nMagHigh or pMagHigh were fused to the N-terminal of eCPX in the pB33eCPX plasmid to express these on the E. coli surface as reported previously. ${ }^{2}$ The plasmid pSB403merR_luxCDABE(merR-lux) codes for the MerR protein and the genes for the bacterial luciferase (luxCDABE), which are regulated by a merR promotor as described previously in the group of Prof. Dr. van der Meer. ${ }^{3}$ E. coli K12 MG1655 was purchased from DSMZ. The Hoechst 33342 dye was purchased from Thermo Fischer. All other chemicals were purchased from Sigma-Aldrich.

\section{Bacterial Strains}

E. coli K12 MG1655 were co-transformed with one of the photoswitchable protein plasmids (either nMagHigh-eCPX or pMagHigh-eCPX, chloramphenicol resistant, $L$-arabinose inducible) and the mercury bioluminescent reporter plasmid (merR-lux, tetracycline resistant). Bacteria co-transformed with eCPX and merR-lux were used as controls.

\section{Bioluminescence Assay for $\mathrm{Hg}^{2+}$ detection}

To assess the luminescence in response to different concentrations of $\mathrm{HgCl}_{2}, \mathrm{nMagHigh}$ - and pMagHighdisplaying merR-lux MG1655 E. coli were cultured overnight in $5 \mathrm{~mL}$ LB medium containing $20 \mu \mathrm{g} / \mathrm{mL}$ chloramphenicol, $10 \mu \mathrm{g} / \mathrm{mL}$ tetracycline at $37^{\circ} \mathrm{C}, 150 \mathrm{rpm}$. Then, $200 \mu \mathrm{L}$ of the overnight culture was added into fresh $10 \mathrm{~mL} \mathrm{LB}$ medium containing $20 \mu \mathrm{g} / \mathrm{mL}$ chloramphenicol and $10 \mu \mathrm{g} / \mathrm{mL}$ tetracycline and cultured for $2 \mathrm{~h}$ at $37^{\circ} \mathrm{C}$, at $150 \mathrm{rpm}$. When the $\mathrm{OD}_{600}$ was about $0.4-0.6$, the cultures were then centrifuged at $25^{\circ} \mathrm{C}, 3500 \mathrm{rpm}$ for 7 minutes and the pelleted bacteria were dispersed into $5 \mathrm{~mL}$ LB. For each sample, $1.2 \mathrm{~mL}$ of the resuspended bacteria were mixed with $400 \mu \mathrm{LLB}, 2 \mathrm{~mL}$ PBS, $8 \mu \mathrm{L} 100 \mathrm{mg} / \mathrm{mL}$ $L$-arabinose in water, and $400 \mu \mathrm{L} \mathrm{HgCl}_{2}$ in water (final $\mathrm{Hg}^{2+}$ concentration: $1.25,2.50,12.5,50,125,500$, and $1250 \mathrm{nM}$ ). The samples were incubated in the dark at $150 \mathrm{rpm}, 30^{\circ} \mathrm{C}$ for $3 \mathrm{~h}$ before transferring 200 $\mu \mathrm{L}$ of the bacterial solution into each well of a 96-well plate. The bioluminescence intensity was then measured using a microplate plate reader (Tecan M1000 Infinite, detection range 398 - $653 \mathrm{~nm}$ ).

\section{Kinetics change of bacterial bioluminescence upon the addition of mercury(II).}

eCPX merR-lux MG1655 E. coli were cultured overnight in 5mI LB (Tetracycline 10ug/ml, Chloramphenicol $20 \mathrm{ug} / \mathrm{ml}$ ) at $150 \mathrm{rpm}, 37^{\circ} \mathrm{C}$. The cultures were then centrifuged at $25^{\circ} \mathrm{C}, 4000 \mathrm{rpm}$ for 7 minutes and the pelleted bacteria were resuspended with PBS to the designed density $\left(\mathrm{OD}_{600}=1.0\right)$. $1 \mathrm{~mL}$ of the 
resuspended bacteria were mixed with $1 \mu \mathrm{L} 1.25 \mathrm{mM} \mathrm{HgCl}_{2}$ in water (final $\mathrm{Hg}^{2+}$ concentration $1250 \mathrm{nM}$ ) and then $100 \mu \mathrm{L}$ were transferred into a 96-well plate. Absorbance at $600 \mathrm{~nm}$ and bioluminescence (detection range $398-653 \mathrm{~nm}$ ) was measured every $5 \mathrm{~min}$ for $18 \mathrm{~h}$ by a plate reader (Tecan M1000 Infinite).

\section{Photoactivation of nMagHigh protein with bioluminescent bacteria}

Overnight cultures of merR-lux MG1655 E. coli from a single colony with $5 \mathrm{~mL}$ LB medium containing 10 $\mu \mathrm{g} / \mathrm{mL}$ tetracycline and $1.25 \mu \mathrm{M} \mathrm{HgCl}_{2}$ at $37{ }^{\circ} \mathrm{C}, 150 \mathrm{rpm}$ were used. $1 \mathrm{~mL}$ of this bacterial culture was centrifuged at $4000 \mathrm{rpm}$ for $10 \mathrm{~min}$ before being resuspended in $500 \mu \mathrm{L}$ PBS. $500 \mu \mathrm{L}$ bacteria and $500 \mu \mathrm{L}$ $150 \mu \mathrm{M}$ purified $\mathrm{nMagHigh}$ protein were mixed and incubated for $10 \mathrm{~min}$ at room temperature in the dark. Subsequently, the bacteria were removed by centrifugation at $4000 \mathrm{rpm}$ for $10 \mathrm{~min} .500 \mu \mathrm{L}$ of 150 $\mu \mathrm{M}$ nMagHigh protein mixed with $500 \mu \mathrm{L}$ PBS was used as a dark control. $200 \mu \mathrm{L}$ of the protein solution was transferred to a 96-well plate and the absorbance from $300 \mathrm{~nm}$ to $550 \mathrm{~nm}$ was measured using a plate reader.

\section{Bacterial aggregation assay}

nMagHigh- and pMagHigh-displaying merR-lux MG1655 E. coli were cultured overnight in $5 \mathrm{~mL}$ LB medium containing $20 \mu \mathrm{g} / \mathrm{mL}$ chloramphenicol, $10 \mu \mathrm{g} / \mathrm{mL}$ tetracycline and $0.04 \% \mathrm{~m} / \mathrm{v}$ L-arabinose (and $5 \mu \mathrm{HgCl}_{2}$ to a final concentration: $1.25,12.5,125$, and $1250 \mathrm{nM}$, if applicable) and incubated in the dark overnight at $37^{\circ} \mathrm{C}, 150 \mathrm{rpm}$. The bacteria were subsequently diluted in PBS to the desired density $\left(\mathrm{OD}_{600}=0.15\right)$. Manipulations were performed in the dark or under red light. Dark samples were covered in aluminum foil to prevent undesired photoactivation. Hoechst 33342 was added into the bacterial solution to a final concentration of $10 \mu \mathrm{g} / \mathrm{mL}$ and incubated for $15 \mathrm{~min}$ at room temperature for the staining. nMagHighand pMagHigh- displaying merR-lux bacteria were mixed in a 1:1 ratio. $300 \mu \mathrm{l}$ of the mixed bacterial cultures was added into 8-well slides ( $\mu$-Slide, 8-well glass bottom, ibidi) containing different concentrations of $\mathrm{Hg}^{2+}$ and the samples were incubated at room temperature for $2 \mathrm{~h}$ in the dark (wrapped in aluminum foil). Bacteria in the absence of $\mathrm{Hg}^{2+}$, but instead kept under blue light illumination (270 $\mu \mathrm{W} / \mathrm{cm}^{2}$ ) and in the dark, respectively, were used as positive and negative controls.

Fluorescence images were acquired on an inverted Confocal Laser Scanning Microscope (CLSM, Leica TCS SP8). For each sample, 25 images $(290 \mu \mathrm{m} \times 290 \mu \mathrm{m})$ were acquired with Hoechst 33342 channel using a $405 \mathrm{~nm}$ laser for excitation and detection of the emission from 420-450 nm. All images were processed in FIJI (FIJI, https://fiji.sc/). To analyze the bacterial aggregation, brightness and contrast of the fluorescent images were automatically adjusted to help identify bacteria, and the images were converted into binary 
images. Using the "Analyze Particles" function in FIJI, clustered bacteria and all bacteria (single and clustered) in each image were detected by taking into account objects with an area $>30 \mu \mathrm{m}^{2}$ and $>2 \mu \mathrm{m}^{2}$, respectively. Aggregation ratio was defined as sum of the area occupied by clustered bacteria divided by the sum of the area occupied by all bacteria. Likewise, the average sizes of clusters were obtained using the results for the particle analysis tool.

\section{Mercury detection in an environmental sample doped with mercury}

nMagHigh- and pMagHigh-displaying merR-lux MG1655 E. coli were cultured overnight in $5 \mathrm{~mL} \mathrm{LB}$ medium containing $20 \mu \mathrm{g} / \mathrm{mL}$ chloramphenicol, $10 \mu \mathrm{g} / \mathrm{mL}$ tetracycline at $37^{\circ} \mathrm{C}, 150 \mathrm{rpm}$. Then, $200 \mu \mathrm{L}$ of the overnight culture was added into fresh $10 \mathrm{~mL} \mathrm{LB}$ medium containing $20 \mu \mathrm{g} / \mathrm{mL}$ chloramphenicol and 10 $\mu \mathrm{g} / \mathrm{mL}$ tetracycline and cultured for $2 \mathrm{~h}$ at $37^{\circ} \mathrm{C}$, at $150 \mathrm{rpm}$. When the $\mathrm{OD}_{600}$ was about $0.4-0.6$, the cultures were then centrifuged at $25^{\circ} \mathrm{C}, 3500 \mathrm{rpm}$ for 7 minutes and the pelleted bacteria were dispersed into $5 \mathrm{~mL}$ LB. For each sample, $1.2 \mathrm{~mL}$ of the resuspended bacteria were mixed with $400 \mu \mathrm{LLB}, 2 \mathrm{~mL}$ water

from the local lake (Aasee), $8 \mu \mathrm{L} 100 \mathrm{mg} / \mathrm{mL} \mathrm{L}$-arabinose in water, and $400 \mu \mathrm{L} \mathrm{HgCl}_{2}$ in water (final $\mathrm{Hg}^{2+}$ concentration: $1.25,12.5,125$, and $1250 \mathrm{nM})$. The samples were incubated in the dark at $150 \mathrm{rpm}, 30^{\circ} \mathrm{C}$ for $3 \mathrm{~h}$.

For the bioluminescence detection, $200 \mu \mathrm{L}$ of the bacterial solution into each well of a 96 -well plate and the bioluminescence intensity was then measured using a microplate plate reader (Tecan M1000 Infinite, detection range $398-653 \mathrm{~nm})$.

The bacteria aggregation, the bacteria were diluted to an $\mathrm{OD}_{600}=0.15$ in PBS, stained with the Hoechst 33342, $300 \mu \mathrm{l}$ of the mixed bacterial cultures was added into 8-well slides and the bacterial aggregation was measured after 2 hours as described above.

\section{Bacterial sedimentation assay}

To assess the sedimentation in response to the $\mathrm{Hg}^{2+}$-triggered bioluminescence, overnight cultures of nMagHigh- and pMagHigh-displaying merR-lux MG1655 E. coli with and without $1.25 \mu \mathrm{M} \mathrm{HgCl}_{2}$ were all prepared as described above and then diluted to $\mathrm{OD}_{600}=1.00$ in PBS and mixed in a 1:1 ratio. E. coli cotransformed with eCPX and merR-lux were used as a control. $200 \mu \mathrm{L}$ of bacterial culture at $\mathrm{OD}_{600}=1.00$ was added into 96-well plates and kept unshaken at room temperature for 2 hours. nMagHigh- and pMagHigh-displaying merR-lux bacteria under blue light $\left(270 \mu \mathrm{W} / \mathrm{cm}^{2}\right)$ and in the dark were used as positive and negative controls, respectively. To quantify the sedimentation after $2 \mathrm{~h}$, the top $50 \mu \mathrm{L}$ of the 
bacterial cultures (top 25\%) was transferred to a new 96 -well plate, diluted with $50 \mu \mathrm{L}$ PBS, and the absorbance at $600 \mathrm{~nm}$ was measured using a plate reader.

To quantify the preconcentration effect achieved through the sedimentation, the nMagHigh- and pMagHigh-displaying merR-lux and eCPX merR-lux bacteria were all prepared as described above with $\mathrm{Hg}^{2+}$ in various concentration. The samples were allowed to sediment for $2 \mathrm{~h}$ and the top $100 \mu \mathrm{L}$ of the bacterial cultures (top 50\%) was removed before measuring the bioluminescence of the remaining bacteria at the bottom (bottom $50 \%$ ) using a plate reader.

\section{Biofilm formation assay}

nMagHigh- and pMagHigh-displaying merR-lux MG1655 E. coli were cultured overnight as described above, but no $\mathrm{HgCl}_{2}$ was added. Overnight cultures of $E$. coli were diluted to $\mathrm{OD}_{600}=0.01$ in $\mathrm{LB}$ containing $20 \mathrm{\mu g} / \mathrm{mL}$ chloramphenicol, $10 \mu \mathrm{g} / \mathrm{mL}$ tetracycline, $0.04 \% \mathrm{~m} / \mathrm{v} \mathrm{L}$-arabinose and $\mathrm{HgCl}_{2}$ at the appropriate concentration, when applicable. The cultures of bacteria expressing nMagHigh or pMagHigh were mixed in a 1:1 ratio. $200 \mu \mathrm{l}$ of bacterial co-cultures was either transferred into a 96-well polystyrene plate (Greiner Bio-one, round bottom) (200 $\mu \mathrm{L} /$ well) for the biofilm crystal violet staining assay, 8-well slides (350 $\mathrm{LL} /$ well) for the biofilm imaging, or a 96-well plate (flat bottom, white) (200 $\mu \mathrm{L} /$ well) for the bioluminescence measurement, and incubated for $48 \mathrm{~h}$ at $37^{\circ} \mathrm{C}$ without shaking. Samples without $\mathrm{HgCl}_{2}$ kept under blue light $\left(135 \mu \mathrm{W} / \mathrm{cm}^{2}\right)$ and in the dark were used as positive and negative controls, respectively.

For the biofilm crystal violet staining assay, the samples in the 96-well plate were rinsed with $200 \mu \mathrm{L}$ water, incubated with $200 \mu \mathrm{L} 1 \%$ crystal violet (CV) solution for $15 \mathrm{~min}$ at room temperature and each well was rinsed three times with $200 \mu \mathrm{L}$ water. The remaining CV was solubilized by the addition of $200 \mu \mathrm{L}$ of $30 \%$ acetic acid in water The solution was then incubated at room temperature for $10 \mathrm{~min}$. $200 \mu \mathrm{L}$ of this solution was transferred to a new flat-bottomed 96-well microplate and the absorbance at $550 \mathrm{~nm}$ was quantified using a plate reader.

For the biofilm imaging, the samples in the 8-well slides were rinsed three times with $300 \mu \mathrm{L}$ water. 300 $\mu \mathrm{L}$ Hoechst $33342(10 \mu \mathrm{g} / \mathrm{mL})$ was added into the well and incubated $30 \mathrm{~min}$ at room temperature. Z-stack images were acquired using the confocal microscopy as detailed above and the biofilm thicknesses were analyzed with 3D reconstruction software from Leica.

For the biofilm bioluminescence measurement, eCPX merR-lux bacteria were used in parallel as controls in the presence of different $\mathrm{HgCl}_{2}$ concentrations. For all samples, the medium was removed after the 
biofilm had formed for $48 \mathrm{~h}$ and the bioluminescence at the bottom of the plate was measured using a plate reader.

\section{REFERENCES}

(1) Rice, J. J., Daugherty, P. S., Directed evolution of a biterminal bacterial display scaffold enhances the display of diverse peptides. Protein Eng. Des. Sel., 2008, 21 (7), 435-442.

(2) Chen, F.; Wegner, S. V., Blue Light Switchable Bacterial Adhesion as a Key Step toward the Design of Biofilms. ACS Synth. Biol., 2017, 6 (12), 2170-2174.

(3) Sciuto, E. L.; Coniglio, M. A.; Corso, D.; van der Meer, J. R.; Acerbi, F.; Gola, A.; Libertino, S., Biosensors in Monitoring Water Quality and Safety: An Example of a Miniaturizable Whole-Cell Based Sensor for $\mathrm{Hg}^{2+}$ Optical Detection in Water. Water 2019, 11 (10), 1986-1988. 

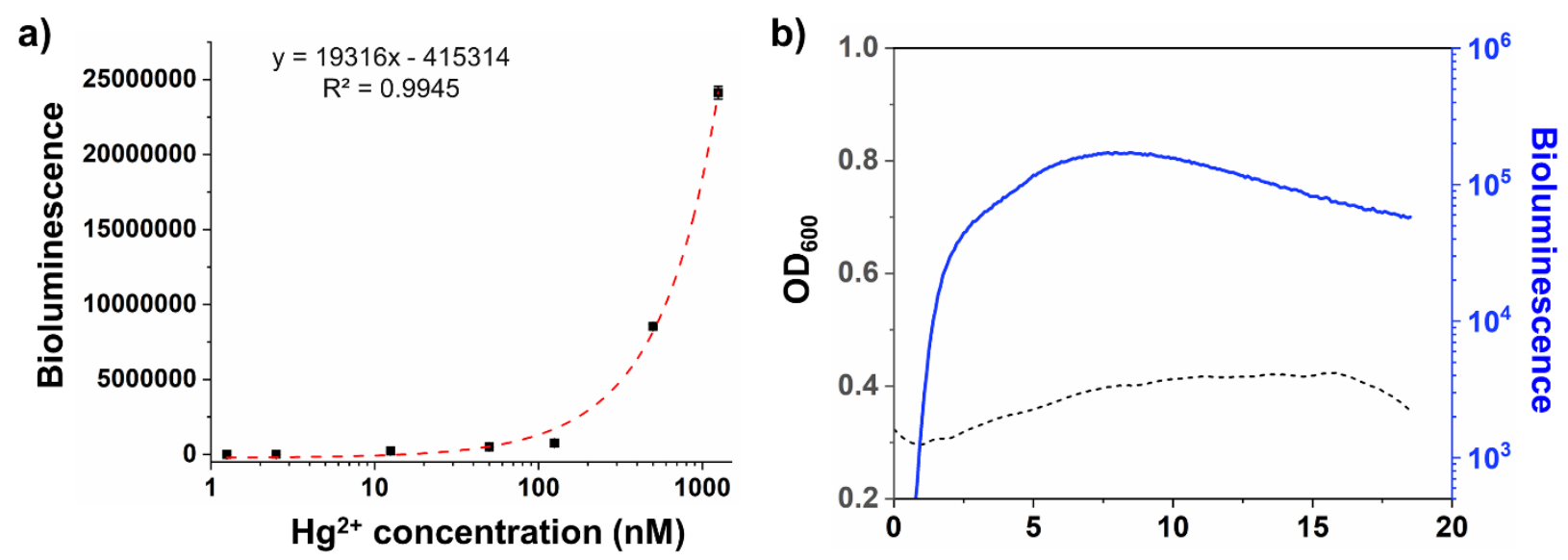

Figure S1. a) Bioluminescence measurement of $E$. coli (co-transformed with merR-lux and nMagHigh) in different concentrations of $\mathrm{Hg}^{2+}(1.25,2.5,12.5,50,125,500,1250 \mathrm{nM})$. The error bars are the standard deviation error from 3 replicates. b) Bioluminescence signal (shown in blue) over time after the addition of $\mathrm{Hg}^{2+}(1250 \mathrm{nM})$ and bacterial growth (shown in black). The bioluminescence increases steadily unit it reaches a plateau after 5 hours. The bacterial density is constant over the course of the experiment and does not contribute to the increase in bioluminescence. 
a)

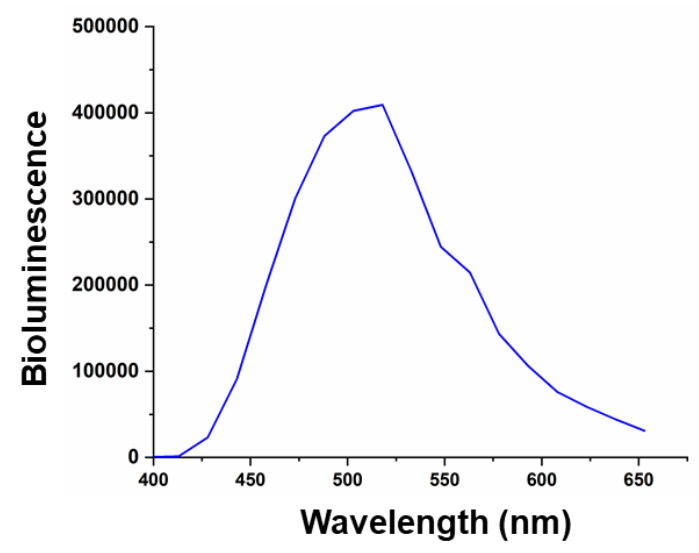

b)

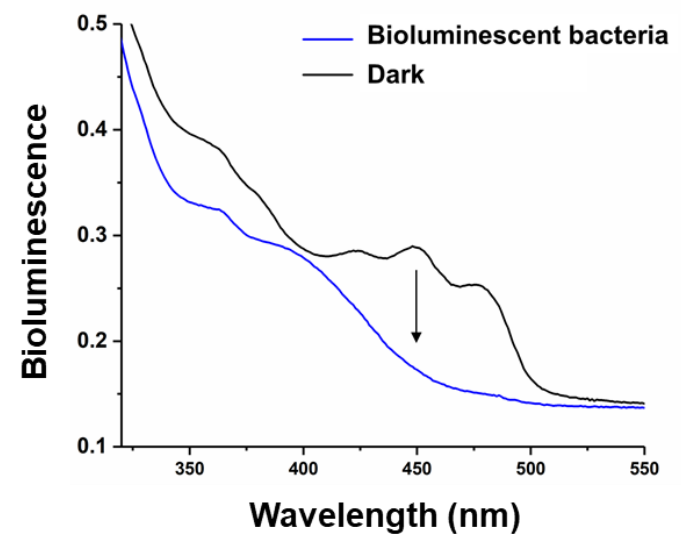

Figure S2. a) Bioluminescence scan of merR-lux E. coli in the presence of $\mathrm{Hg}^{2+}(1.25 \mu \mathrm{M})$. b) UV-vis spectra of photoswitchable protein nMagHigh in the dark or incubated with bioluminescent bacteria. The absorption of nMagHigh protein at $450 \mathrm{~nm}$ decreased when incubated with bioluminescent bacteria for $10 \mathrm{~min}$, showing the photoactivation of the nMagHigh protein. 


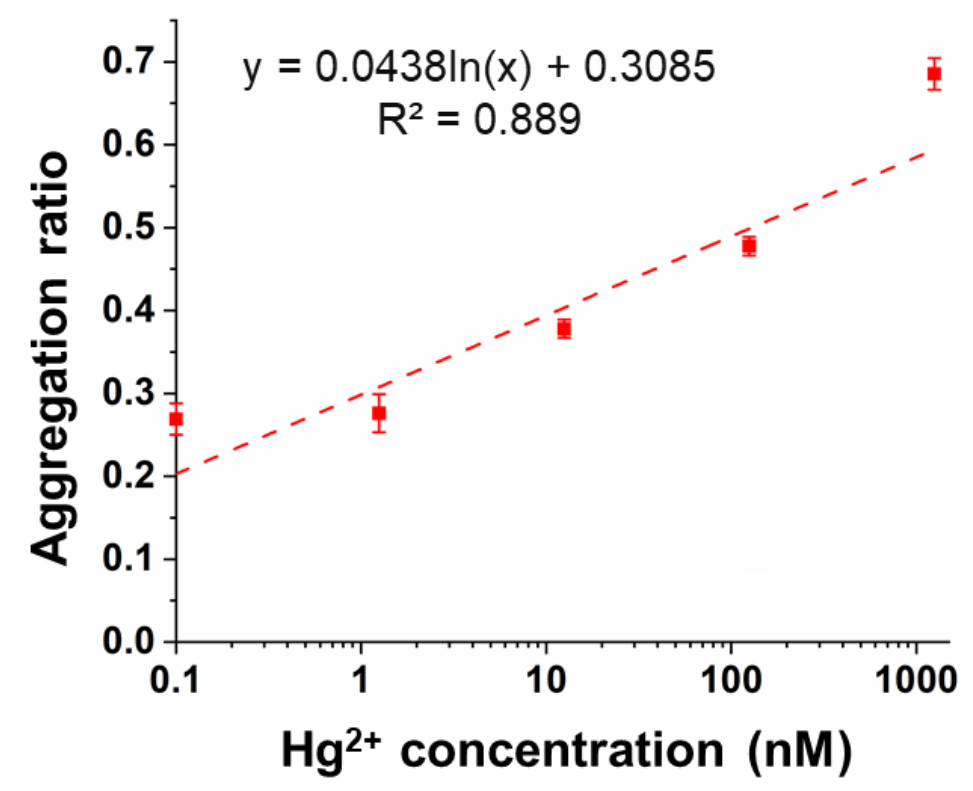

Figure S3. The aggregation ratio of nMagHigh and pMagHigh displaying merR-lux E. coli increased linearly with the logarithm of the $\mathrm{Hg}^{2+}$ concentration. 
a)

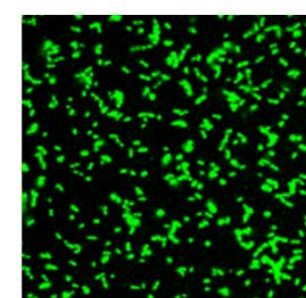

$\mathrm{Hg}^{2+} \quad \mathbf{O} \mathrm{nM}$

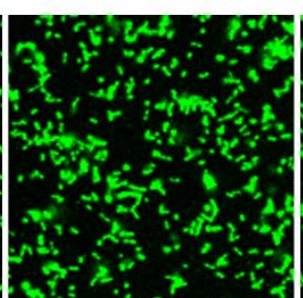

$1.25 \mathrm{nM}$

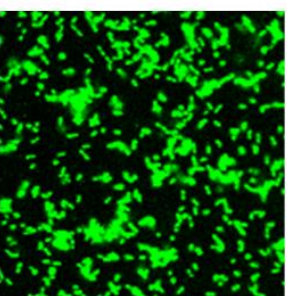

$12.5 \mathrm{nM}$

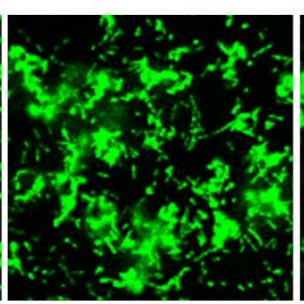

$125 \mathrm{nM}$

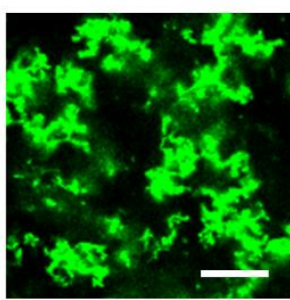

$1250 \mathrm{nM}$

b)

c)
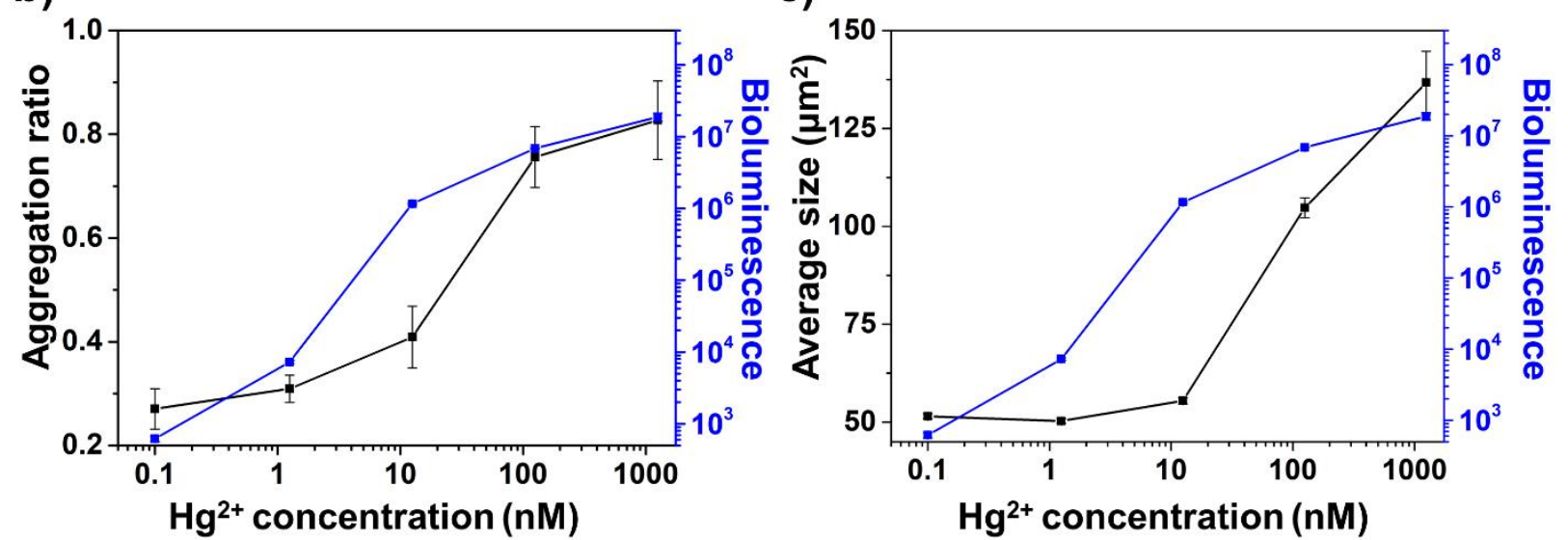

Figure S4. Mercury detection in an environmental sample taken from the local lake (Aasee), which was doped with mercury. a) Microscopy images of nMagHigh and pMagHigh displaying merR-lux E. coli (stained with Hoechst 33342, shown in green) $\left(\mathrm{OD}_{600}=0.15\right)$, which were incubated with different concentrations of $\mathrm{Hg}^{2+}$ for $2 \mathrm{~h}$. Scale bar is $20 \mu \mathrm{m}$. b) Aggregation ratio and bioluminescence signal from cultures in (a). c) the average cluster size and bioluminescence signal of cultures in (a). The error bars are the standard error from 25 images. 
a)

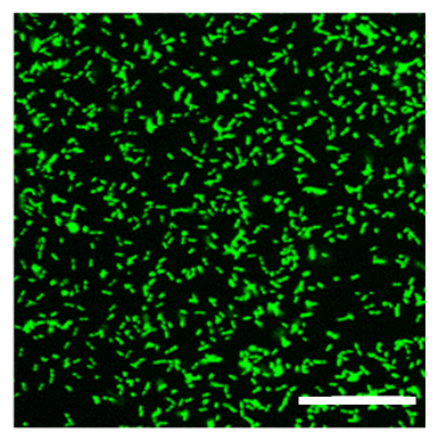

b)

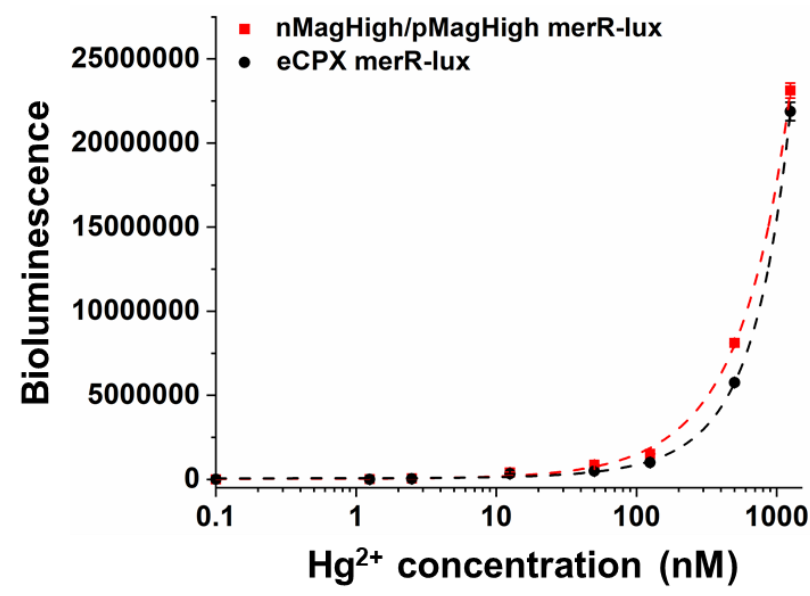

Figure S5. a) eCPX merR-lux E. coli were used as a negative control and showed no aggregation after incubation with $1250 \mathrm{nM} \mathrm{Hg}^{2+}$. Scale bar is $20 \mu \mathrm{m}$. b) The bioluminescence of 1:1 coculture of nMagHigh/pMagHigh displaying merR-lux E. coli and eCPX merR-lux E. coli increased linearly with the $\mathrm{Hg}^{2+}$ concentration. Curve fitting formulas are $y=18328 x-184131\left(R^{2}=0.9967\right)$ and $y=17076 x-$ $453970\left(R^{2}=0.9807\right)$, respectively. The error bars are the standard deviation error from 3 replicates. 


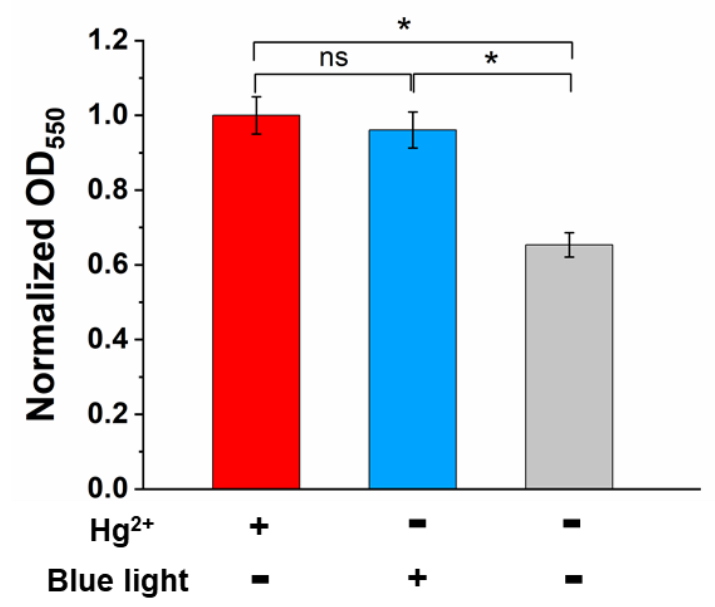

Figure S6. Biofilm formation assay using crystal violet staining for quantification. nMagHigh and $\mathrm{pMagHigh}$ displaying merR-lux E. coli were mixed in a $1: 1$ ratio $\left(\mathrm{OD}_{600}=0.01\right)$ and incubated for $48 \mathrm{~h}$ with $\mathrm{Hg}^{2+}$ or under blue light or in the dark. Biofilm formation was quantified using crystal violet (CV) staining. The absorbance at $550 \mathrm{~nm}$ was measured. ${ }^{*} p<0.05$. The error bars are the standard deviation error from 3 replicates. 